\title{
EVALUATION OF THE ENGLISH TEXTBOOK OF STANDARD SEVEN OF GUJARAT IN THE LIGHT OF NCF
}

\section{Prof. Dr. Jagdish S Joshi \\ Mr. Savaliya Jaydipbhai K}

\begin{abstract}
English language is lot more than just an official language in India. It has been the language of the diplomacy, higher administration, higher education, superior judiciary etc. English is a language of opportunities and success for life in India. There have been different commissions and Education Policies were published to improve our Education. National Curriculum Framework 2005 is the latest. NCF 2005 is most vital part for develops textbooks. So evaluate textbook of English of standard seven of Gujarati medium which is published by Gujarat state textbook board in the light of NCF 2005. Textbook of English is evaluated as per parameters which are selected from NCF-2005. Sixteen parameters are used to evaluate the English textbooks of Standard seven. Parameters are like: Connecting knowledge to out of the school, Learning is Shifted away from rote method, Overall development of children, making children sensitive to the environment, Child centred education, Active and creative capabilities, etc. English textbook of standard seven has all the qualities or it is as per the NCF-2005's suggestion except two parameter: Peace, and Making children sensitive to the environment.
\end{abstract}

Key Words: English language teaching, NCF-2005, Evaluation, English textbook 


\section{Introduction}

English is speaking not only in United Kingdom and United State of America but also in all British colonies. English is utilised as a first and second or foreign language in the world. English rejoice it place in the world. It is the only language which is the largest used in the world. Speaking English is believed as powerful or high class among aboriginal of the colonial countries. Peoples from India who know English frequently blend it with vernacular languages in their discourse. English is also uses as a communicator or a link language among Indians who speak different language. English is most vital in some system like legal, financial, education and business in India.

There have been different commissions and Education Policies were published to improve Education. NCERT published first National Curriculum Framework in 1975 to prepare curriculum and textbooks. One of the main objective of NCF 2005 is overall development of children. NCF 2005 is significant for prepares textbooks so evaluate textbooks of English of standard seven of Gujarati medium which is published by Gujarat state textbook board in the light of NCF 2005.

\section{National Curriculum Framework}

Indian constitution permitted the state government to take decisions regarding to school education incorporating curriculum till 1967. The centre could only facilitate direction to the state on policy subjects. Early effort of National Education policy of 1968 the Curriculum Framework designed by NCERT in 1975 were formulated. NCERT prepared NCF in 1975 subsequent the recommendations of Education Policy on 1968. The country as a whole had a National Policy on Education which imagine National Curriculum Framework as a means of modernising education. NCERT was given the duty of developing the National Curriculum Framework and reviewing the framework at regular times. The first NCF came in 1975 and last in 2005. NCERT develops National Curriculum Framework which offers plans or strategies for developing textbooks and school curriculum. NCF-2005 equipped by NCERT to deliberates an extensive assortment of issues regarding school education.

\section{Evaluation of Textbook}

For the present paper, researchers selected textbooks of English of standard seven of Gujarati medium which is published by Gujarat state textbook board. All the lessons of the textbooks are evaluated in the light of the NCF-2005. For evaluation researchers decide parameters from NCF.

\section{- Connecting knowledge to life outside the school}

This is one of the most important point of NCF-2005. NCF puts more weightage on this because students' knowledge which they get from the school, it connects or utilises it in their day to day life. It does not only the textbook centric knowledge or uses only for the examination. $\mathrm{NCF}$ believes in to use that knowledge in real life where students has been passed their most of the time.

Lesson No: 3, Activity No: 8: Project (English VII: First sem., SL 33) 
Students are instructed to fill up the table with the help of their collected rappers. Students take the help of science teacher and discuss the ingredients. They are harmful or harm less.

Lesson No: 5, Activity No: 1: Play the game (English VII: Second sem. SL 54)

It asks the students to play the 'Fixed answer' game and 'Where is my answer' game. Teacher also help the students to play this game. First of all teacher fixed any one answer by the students. After that teacher asks any question to them. Students will give the fixed answer.

\section{- Learning is shifted away from rote method}

Rote learning is a memorization technique base on repetition. The idea is that one will be able to quickly recall the meaning of material the more one repeats it. NCF-2005 decides to shift learning from rote method.

There is no any activity related to this parameter.

\section{- Overall development of children}

This point throws light on students' development which is not only related with textbook. But different factors of students' life like intellectual, physical, mental, etc.

Lesson No: 3, Activity No: 4: Play the game 'I Say' (English VII: First sem., SL 28)

Students are played the game by the teacher. After the game, students read different circumstances which are given and what is students' reaction for the particular circumstances? Choose the proper reaction from the bracket.

Lesson No: 4, Activity No: 1: See the picture. Listen to the teacher. (English VII: First sem., SL 35)

Students are instructed to see the given picture. Teacher describes picture. Students listen him and follow the instruction which is given by teacher.

Lesson No: 3, Activity No: 7A: Fill the information in the table (English VII: Second sem., SL 35)

It asks the students to fill up the information in the table. This table is about the information of the students' and their families' everyday life. There are four columns like: self, mother, father and cousin. There are information like: name, reading time, time of going, playing and other activities, time of watching T.V. and sleeping time.

\section{- Making children sensitive to the environment}

There is no any activity about environment in the textbook of Standard seven.

\section{- Peace}

There is not even a single activity on peace.

- Strengthen our cultural heritage and national identity

Lesson No: 1, Activity No: 5A: Read (English VII: Second sem., SL 5) 
This is an informative activity. This activity is related to the national identity. It is about the Gir national Park and Asiatic lion which is only in Gujarat.

Lesson No: 4, Activity No: 7: Read and arrange (English VII: Second sem., SL 46)

It asks the students to read the given activity. It is about Navratri, one of the famous festival of Gujarat.

\section{- Child centred education}

Child centred education means children is in centre. Before few years teacher was in centre. He read and explains lessons and activities and students just listens him. Means, teacher was only an active person in the class. Students were passive learners. But the scenario is changed now. Role of teacher is changed. Student is in centre and teacher is a facilitator for students. Most of activities are based on student, means students are in centre. Students' voice, point of views, what they think, all these points are very important as per NCF 2005 and said textbooks are as per this suggestion of NCF.

Lesson No: 2, Activity No: 6: Complete the dialogue. (English VII: First sem., SL 20)

Students are instructed to work in group. They complete the dialogue on the bases of the story which is in activity number three. Students also enact in the class.

Lesson No: 1, Activity No: 2: Play the game (English VII: Second sem., SL 1)

It asks the students to play the game. Teacher also helps the students to play the game. There are some chits on the table. Students pick up any one chit and do the action which is mentioned in the chit. Then they reads aloud in the class and all the students of the class do the action which is mentioned in the chit. Students come one by one and play the game.

\section{- Active and creative capabilities}

Lesson No: 1, Activity No: 5: Discuss in pairs and write your points (English VII: First sem., SL 6)

It asks the students to discuss in pair and write down which other things are seen by Tejasvini from the sky.

Lesson No: 4, Activity No: 4: Discuss in group (English VII: First sem., SL 40)

Students are instructed to discuss in group of three or four. If the King want to hide the princess for the fourth time where will he hide her?

\section{- Children find their voices and nurture their curiosity}

Lesson No: 1, Activity No: 12: Imagine a device like flying bicycle, drew its picture (English VII: Second sem., SL 13)

It asks the students about his thought to prepare a new device like flying bicycle. Here students draw the picture of that device. Write parts name in English. Student also mentions that which scientific rules used in it.

Lesson No: 3, Activity No: 2: Complete the dialogue (English VII: Second sem., SL 15)

It asks the students to complete the dialogue as per the example. 


\section{- Children learn in variety of ways.}

Children can learn through experience, making and doing things, experimentation, reading, discussion, asking, listening, thinking and reflecting, and expressing oneself in speech, movement or writing-both individually and with others. They require opportunities of all these kinds in the course of their development. All these varieties come under this section.

Lesson No: 1, Activity No: 5: Teacher tell the story, listen carefully and do the silent reading (English VII: First sem., SL 5) reading.

Students are instructed to listen the story. Teacher tells the story then they do the silent

Lesson No: 2, Activity No: 1B: Read the passage (English VII: First sem., SL 15)

It asks the students to read the passage. This passage is about one of the great Indian leader Shubhash Chandra Bose.

\section{- Learn through direct experience}

Lesson No: 2, Activity No: 4: Play the game (English VII: First sem., SL 18)

It asks the students to play the game of 'Fix Answer' and 'Where is my Answer' with the help of teacher. There are some sentences, given in the help line for 'Fix Answer' game. Teacher makes two group for the game 'Where is my answer'. First of all prepares a bunch of question and its answers'. Then asks the question and match or find out its correct answer.

Lesson No: 3, Activity No: 8: Project (English VII: First sem., SL 33)

Students are instructed to collect the rappers and on the bases of it complete the table. Student have to write a things like: product name and ingredients. Students take the help of the science teacher to decide the ingredients are harmful or harmless.

- Learners to engage with concepts and deepen understanding, variety and challenge and be interesting and engaging

Lesson No: 2, Activity No: 3: Answer the question (English VII: First sem., SL 17)

It asks the students to answer the questions. There are four Questions. There are three question out of four is MCQ type and one is descriptive.

Lesson No: 4, Activity No: 4: True and false (English VII: First sem., SL 40)

Students are instructed to identify the given sentences whether they are true or false on the bases of the story.

\section{- Team work}

NCF-2005 gives weightage on team work. There are many activities on the team work in the textbooks of English of standard seven. Here mentions activity which is on team work or pair work.

Lesson No: 2, Activity No: 6: Work in group and complete the dialogue (English VII: First sem., SL 20) 

it in the class.

It asks the students to work in group and complete the dialogues based on story and enact

Lesson No: 4, Activity No: 2: See the picture and work in group and described it in dialogue (English VII: First sem., SL 36)

Students are instructed to look at the picture and work in the group and describes it in the dialogue form.

\section{- Attainment of a basic proficiency and development of language}

Lesson No: 2, Activity No: 3: Read and enjoy (English VII: First sem., SL 16)

Students are instructed to read the story and enjoy it.

Lesson No: 2, Activity No: 1: Listen and act (English VII: Second sem., SL 15)

It asks the students to listen the instruction and act.

- Designers of textbooks provide guidance to teacher regarding ways I which the subject matter can explored

Lesson No: 2, Activity No: 1A: True and false (English VII: First sem., SL 14)

Here instruction for the teacher. Teacher speaks the sentences based on picture. Then decide the sentences are true or false. The help line is about which type of sentences are spoken by teacher.

Lesson No: 3, Activity No: 4: Play the Game (English VII: Second sem., SL 34)

Here help line is given for the teacher. Which types of response and circumstances teacher can use? It is given in the helpline.

- Performing a small drama or enact a dialogue

Lesson No: 2, Activity No: 6: Complete the dialogue and enact it (English VII: First sem., SL 20)

Students are instructed to work in group and complete the dialogue. After complete the dialogue students enact it in the class room.

Lesson No: 1, Activity No: 3D: Read the dialogue and enact (English VII: Second sem., SL 3)

Students are instructed to read the dialogue silently and then enact it.

Table and Graph

Table 1

NCF points' average table

\begin{tabular}{|l|l|l|l|l|l|l|l|l|l|l|l|l|l|l|l|l|}
\hline $\begin{array}{l}\text { NCF } \\
\text { Point } \\
\text { s }\end{array}$ & 1 & 2 & 3 & 4 & 5 & 6 & 7 & 8 & 9 & 10 & 11 & 12 & 13 & 14 & 15 & 16 \\
\hline Aver & 9. & 0. & 22. & 0. & 0. & 1. & 97. & 11. & 10. & 70. & 14. & 40. & 9. & 89. & 12. & 2. \\
\hline
\end{tabular}


Towards Excellence: An Indexed, Refereed \& Peer Reviewed Journal of Higher Education / Dr. Jagdish Joshi \& Mr. Jaydeep Savaliya/ Page 189-196

\begin{tabular}{|l|l|l|l|l|l|l|l|l|l|l|l|l|l|l|l|l|}
\hline age & 46 & 00 & 30 & 00 & 00 & 35 & 97 & 49 & 81 & 95 & 86 & 54 & 46 & 86 & 16 & 70 \\
\hline
\end{tabular}

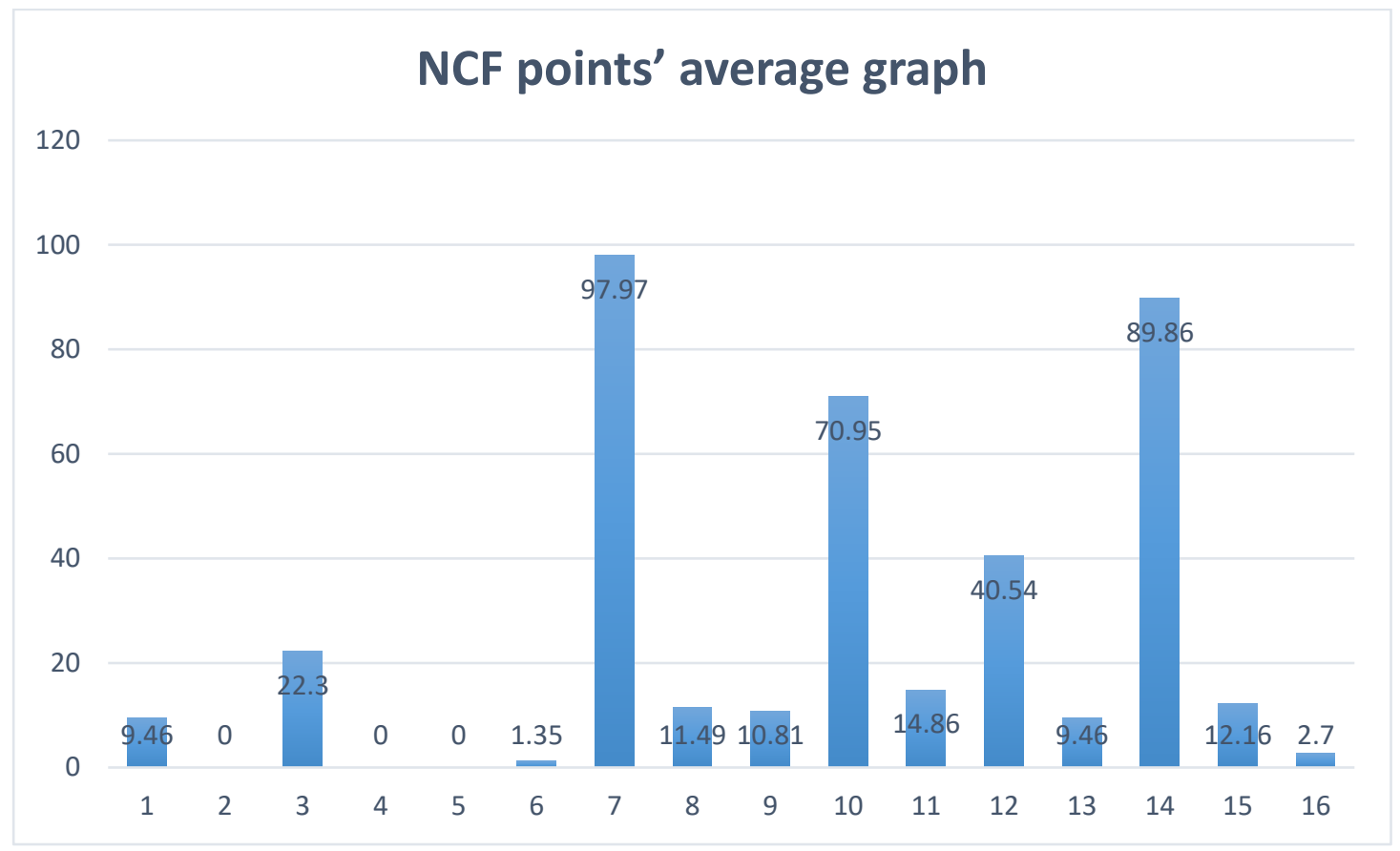

Fig. 1. NCF points' average graph

\section{Conclusion}

English language is lot more than just an official language in India. It has been the language of the diplomacy, higher administration, higher education, superior judiciary etc. English is a language of opportunities and success for life in India. There have been different commissions and Education Policies were published to improve our Education. National Curriculum Framework 2005 is the latest. NCF 2005 is most vital part for develops textbooks so evaluate textbooks of English of standard seven of Gujarati medium which is published by Gujarat state textbook board in the light of NCF 2005.Textbooks of English is evaluated in light of parameters which are selected from NCF-2005. Sixteen parameters are used to evaluate the English textbooks of Standard seven. English textbook has all the qualities or as per the NCF2005's suggestion except two parameters. There is no any activity which is based on peace, and Making children sensitive to the environment. At the end of the paper only said that said textbook is very good and textbook preparation team work really good to follow NCF.

\section{Work cited}

Behera,Arun K. "ELT in India: An Analysis." International Journal on Studies in English Language and Literature.1.1 (2013): 1-5. Web. 28 Feb. 2017.

Gujarat state. GCERT. English: Standard 7 (First semester). Gandhinagar: Gujarat state School Textbook Board, 2016. Print.

---. ---. English: Standard 7 (Second semester). Gandhinagar: Gujarat state School Textbook Board, 2015. Print. 
M. Vijayalakshmi and ManchiSaratBabu. "A brief History of English Language Teaching in India." International Journal of Scientific and Research Publications. 4.5 (2014): 1-5. Web. 28 Feb. 2017.

Malini, S. Devika. "English Language Teaching in India- A Critical Evaluations of ELT in India." International Multidisciplinary Research Journal. 1.7 (2011): 52-54. Web. 28 Feb. 2017.

Modern Language Association. MLA Handbook for Writers of Research Papers. 8th ed. New Delhi: East-West Press Pvt Ltd., 2009. Print.

"National Curriculum Framework." Wikipedia: The Free Encyclopedia. en.wikipedia.org. N.p., Web. 28 Feb. 2017.

Pallath, Pratheesh. "History of Development of Curriculum Framework." pratheeshpallath.blogspot.in.N.p., Oct. 2016. Web. 28 Feb. 2017.

Parab, Vitthal. "A Critical Analysis of the Contemporary Status of English Language Teaching in India."International Journal of Applied Research. 1.9 (2015): 1-3. Web. 28 Feb. 2017.

Patel, Rakesh and other. English: Second Language Standard-6 First semester. Gandhinagar: Gujarat state textbook board, 2016. Print.

Pondra, Rajender. "English Language Teaching in India: A Review." Paripex-Indian Journal of Research. 5.2 (2016): 23-25. Web. 28 Feb. 2017.

Pal, Yesh. National Curriculum Framework 2005. New Delhi: NCERT, N.d. Print.

Prof. Dr. Jagdish S Joshi

Professor-Director

UGC HRDC Gujarat University, Ahmedabad

joshijagdish@yahoo.com, M. 9426587963

\&

Mr. Savaliya Jaydipbhai K

Research scholar

Gujarat University

jaydipsavaliya007@gmail.com, M. 9924257443 